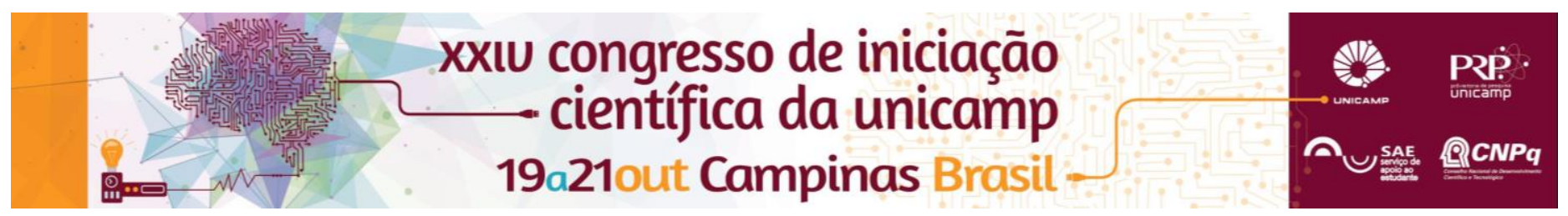

\title{
Determinação do módulo bulk de uma esfera submetida a uma carga triaxial através da técnica de moiré
}

\author{
Henrique Dercoli*, Prof. Dr. Inácio M. D. Fabbro
}

\begin{abstract}
Resumo
O presente projeto tem como objetivo utilizar a técnica de moiré para a determinação de constantes elásticas em ensaios não destrutivos. Para tal, foi utilizada a técnica de moiré de projeção em um corpo esférico feito de borracha silicone inserido em uma câmara de compressão triaxial de parede transparente, onde a esfera foi submetida a cargas hidrostáticas. Através de imagens tiradas da esfera, utilizando tratamentos de imagem através do software ImageJ, é possível determinar o volume da esfera no momento da captura de cada imagem. Sabendo a variação de volume correspondente a uma determinada variação de carga hidrostática, é possivel determinar o módulo bulk (ou módulo volumétrico) do corpo de prova.
\end{abstract}

Palavras-chave:

moiré, bulk módulus, elasticidade.

\section{Introdução}

Reologia é um campo da ciência que procura estudar o comportamento físico dos corpos, entendendo o comportamento estrutural intrínseco da matéria. Este estudo é caracterizado pelo estudo do material, sem necessidade do conhecimento da forma dos corpos envolvidos. Dentro da reologia, o campo da macroreologia busca estabelecer as características constitutivas de cada material, não havendo preocupação com as origens físico-químicas destas. ${ }^{[1]} \mathrm{O}$ comportamento dos materiais constituintes dos corpos pode ser simplificado em três modelos estruturais básicos: elástico, plástico e viscoso. ${ }^{[1]}$ Todos os materiais possuem, até certa extensão, a propriedade de elasticidade. O comportamento elástico é observado em situações nas quais um corpo sólido é submetido a carregamentos externos. Estes carregamentos provocarão uma deformação até um determinado limite de escoamento, que ocorre quando as deformações não são mais reversíveis. Caso este limite não seja alcançado, a partir do momento que estas forças não forem removidas, a deformação será dissipada. ${ }^{[3]}$ Nos estudos reológicos dos materiais, uma das dificuldades encontradas é, dado um carregamento aplicado, determinar a deformação sofrida pelo corpo. Uma possibilidade para a mensuração da deformação do objeto se dá através de técnicas perfilométricas, as quais são técnicas ópticas utilizadas na detecção da topografia de um objeto. Devido à simplicidade de execução e medição, as técnicas de moiré são umas técnicas perfilómétricas mais utilizadas. ${ }^{[2]}$

\section{Resultados e Discussão}

As técnicas convencionais de mensuração de volume apresentam desvantagens intrínsecas às suas técnicas de mensuração das variações volumétricas. A metodologia mais comum para avaliar o módulo bulk consiste na imersão do espécime em uma câmara de pressão preenchida completamente por um líquido (água ou outro fluido hidráulico). A câmara então é pressurizada utilizando um gás pressurizado. A variação volumétrica do espécime então é detectada pela variação do nível do líquido na câmara. O protótipo testado substitui o líquido por pressurização utilizando somente ar no interior de sua câmara. A detecção da variação volumétrica do corpo de prova por sua vez se dá através de imagens registradas antes e ao longo dos ensaios, onde são utilizados softwares para tratamento das imagens e detecção das bordas do espécime e assim o seu diâmetro.
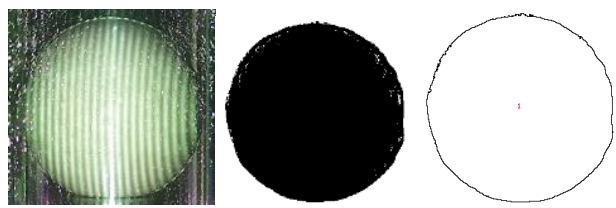

Figura 1: (Esquerda para direita) Fotografia da esfera no interior da câmara | Sombra da esfera | Silhueta da esfera

Apesar de trazer uma melhora na mensuração das dimensões do espécime, a metodologia apresentou problema relacionados à confecção do protótipo, como vazamentos de ar por frestas nos instrumentos utilizados para a medição das pressões internas à câmara, impedindo que se elevasse a pressão interna a cima de 5 bar.

\section{Conclusões}

A metodologia utilizada nas medições das dimensões do espécime apresentou resultados conforme o esperado, mostrando-se uma boa metodologia para a mensuração de corpos em câmaras translúcidas. O protótipo da câmara apresentou adversidades quanto a aplicação de cargas no interior da esfera, sendo necessário um refinamento dos instrumentos utilizados na medição das pressões internas.

${ }^{1}$ FILHO, J. M.; JUNIOR, J. de. A. F.; da COSTA, M. M. M. Materiais de Construção - Reologia, Departamento de Construção Civil - Universidade Federal do Paraná, 2007

${ }^{2}$ LINO, Antonio Carlos L. Técnica óptica de moiré visando a aplicação no estudo de superfícies irregulares, Dissertação de Mestrado, FEAGRI Unicamp, Campinas, SP; [s.n.], 2002

${ }^{3}$ TIMOSHENKO, Stephen P. e GOODIER J. N. Theory of elasticity, $3^{\mathrm{a}}$ Edição, McGraw-Hill Publishing, 1951 